\title{
INTRAEMPREENDEDORISMO NA ADMINISTRAÇÃO PÚBLICA: DIAGNÓSTICO PÓS REFORMA GERENCIAL
}

Michelle Oliveira Do Espírito Santo Corsino ${ }^{1}$ Milton Augusto Pasquotto Mariani ${ }^{1}$

${ }^{1}$ Universidade Federal de Mato Grosso do Sul 


\section{INTRAEMPREENDEDORISMO NA ADMINISTRAÇÃO PÚBLICA: DIAGNÓSTICO PÓS REFORMA GERENCIAL}

Resumo: O presente estudo objetiva verificar até que ponto a existência de características empreendedoras interfere na melhoria do desempenho organizacional e sugere propostas de estímulo à criação e manutenção de um ambiente intraempreendedor na Administração Pública. Busca-se caracterizar o perfil dos técnico-administrativos do Campus de Três Lagoas, da UFMS. Foi aplicado o Teste Tendência Empreendedora Geral (TEG), desenvolvido, em 1988, pela Durhan University Business School. Constatou-se que apenas a característica "Impulso/Determinação", comum aos empreendedores de sucesso, obteve resultado acima da média esperada. Este resultado aponta para a necessidade de mudanças e adaptações institucionais que oportunizem melhores respostas às demandas em um cenário competitivo, instável, dinâmico e desafiador. Embora as reformas administrativas, com ênfase para a Reforma Gerencial, tenham buscado a modernização da Administração Pública, ainda existe um considerável percurso para a construção de um ambiente intraempreendedor que corrobore com a melhoria no desempenho dos servidores e, consequentemente, das Organizações Públicas.

Palavras-chave: Administração Pública. Reformas Administrativas. Intraempreendedorismo. Desempenho Organizacional.

\section{Introdução}

Com o início da reforma gerencial da Administração Pública, ocorrido de forma acentuada no Brasil nos anos 90, surgiu uma grande preocupação relacionada à cobrança de resultados efetivos das ações dos servidores públicos. Esta nova forma de gestão buscou vencer os estágios patrimonialistas e burocráticos que configuravam obstáculos ao bom funcionamento do aparelho estatal, além de incorporar valores como eficiência, eficácia e efetividade aos serviços prestados à sociedade.

De acordo com os estudos de Leite (2013, p. 8), o conceito de eficiência compreende o uso racional dos recursos públicos, o esforço de "fazer mais com menos", garantindo maior potencial às receitas orçamentárias. Importa acrescentar que esta vertente ganhou impulso no Brasil com base na Lei de Responsabilidade Fiscal (Lei Complementar 101, de 4 de maio de 2000); já a eficácia se refere ao verdadeiro alcance dos objetivos propostos pela Administração Pública, que busca atender às demandas sociais, tanto quantitativa como qualitativa, com foco nos benefícios e na qualidade do serviço que é prestado à sociedade. Nesse segmento, cumpre mencionar que a efetividade consiste nos impactos de médio e longo prazo, uma vez que está relacionada a um contexto macro de "necessidade de consciência política e da consolidação da democracia".

Historicamente, o processo de mudança nas formas de gestão dos governos, já havia sido iniciado, em nível mundial, na década de 1980 a partir de modelos de reformas administrativas ocorridas no Reino Unido e nos Estados Unidos. Ancorando-se nos pressupostos de Peci et al. (2008), é necessário observar que vários movimentos nas décadas de 1980 e 1990 foram englobados no conceito de New Public Management (NPM) ou Nova Administração Pública (NAP), emergindo nos países anglo-saxões e nos Estados Unidos. Tal
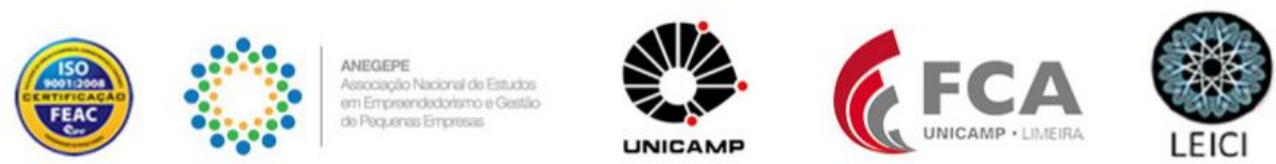
postulado, busca um novo padrão para a Administração Pública, com foco em pontos centrais como a adaptação e a transferência dos conhecimentos gerenciais presentes no setor privado para o público.

Segundo as contribuições de Osborne \& Gaebler (1994), a proposta da NAP é (re)inventar o Governo, uma pretensão audaciosa para uma significativa parcela da sociedade, que o considera como algo fixo e imutável. Estes estudiosos demonstram, em sua obra, a relevância da aplicação dos conceitos de gestão da iniciativa privada na Administração Pública, tais como: desempenho, redução de custo, eficiência, produtividade e foco nos clientes. Para os pesquisadores "[...] qualquer instituição, pública ou privada, pode ser empreendedora, assim como, qualquer instituição pública ou privada, pode ser burocrática" (Osborne, \& Gaebler, 1994, p.23). Dessa forma, torna-se possível construir uma gestão pública equilibrada entre empreendedorismo e burocracia que seja adequada ao ambiente contemporâneo, com instituições e agentes públicos flexíveis, adaptáveis e criativos, os quais ofereçam resultados de qualidade conferindo poder aos cidadãos, indo além da prestação de serviços.

Com efeito, os servidores públicos são aqueles que agem em nome do Estado e administram os bens públicos. São os principais responsáveis pelo bom funcionamento da máquina estatal. Diante disso, para a concretização da nova gestão é necessário que o setor público disponha de pessoas ágeis, flexíveis, inovadoras, criativas e que não tenham medo de correr riscos calculados, características típicas de indivíduos que possuem perfil empreendedor (Dornelas, 2008).

A partir deste contexto, a presente pesquisa objetivou estudar o perfil empreendedor encontrado na equipe de técnico-administrativos do Campus de Três Lagoas (CPTL) da Universidade Federal de Mato Grosso do Sul (UFMS), partindo da identificação das cinco características tipicamente encontradas em pessoas que possuem tal perfil, mensuradas pelo Teste Tendência Empreendedora Geral (TEG), desenvolvido na Inglaterra em 1988 (Caird, 1988). Com a identificação de tais características: Necessidade de Sucesso, Necessidade de Autonomia/Independência, Tendência Criativa, Propensão a Riscos e Impulso/Determinação procurou-se demonstrar como o perfil empreendedor dos agentes públicos pode contribuir com o fomento do intraempreendedorismo e com a melhoria do desempenho organizacional, indo ao encontro dos objetivos preconizados pela Administração Pública Gerencial.

\section{Referencial Teórico}

\subsection{O Empreendedorismo na Administração Pública: deslindando conceitos}

Além do seu tradicional papel voltado para a criação de novos negócios, um novo enfoque vem sendo dado ao tema empreendedorismo. Trata-se, na esteira de Dornelas (2004), de Empreendedorismo Corporativo, o qual está atrelado à prática do empreendedorismo dentro de empresas já estabelecidas. Compreende-se por Empreendedorismo Corporativo/Intraempreendedorismo o processo pelo qual o indivíduo (ou equipe) instigam a renovação/inovação dentro de um processo organizacional existente.

Atualmente, fomentar e valorizar o perfil dos intraempreendedores tem sido o grande desafio para as organizações privadas. Todavia, em solo brasileiro, com o advento da Reforma Gerencial, a partir da década de 90 , as organizações públicas também começaram a almejar profissionais com características empreendedoras.

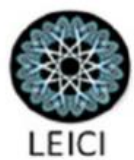


Notadamente, os estudos sobre empreendedorismo são mais comuns em organizações privadas no Brasil; ao passo que, no setor público, são esparsos e incipientes. Osborne \& Gaebler (1994), desbravadores deste tema, no âmbito mundial, escreveram a obra intitulada Reinventando o Governo: como o espírito empreendedor está transformando o setor público. Com este trabalho, os pesquisadores partem da premissa de que o governo desenvolvido durante a era industrial (caracterizado por burocracia, morosidade, centralização, hierarquização), concentrava-se somente no cumprimento de normas e regulamentos. Não obstante, o governo com este perfil deixou de atender às demandas da sociedade contemporânea.

Convém trazer à baila, as ponderações de Hashimoto (2013) acerca do conceito de intraempreendedorismo. Para o pesquisador, o fomento do intraempreendedorismo é a chave para a vantagem competitiva das Organizações, uma vez que esse processo se concentra no indivíduo e na sua propensão em agir sozinho, de maneira empreendedora. Entretanto, para que esse movimento não seja fragmentado e descontínuo, as Organizações precisam contribuir, significativamente, com a construção do profissional com perfil intraempreendedor.

Partindo dos pressupostos de Pinchot (1985), o indivíduo intraempreendedor apresenta características como criatividade, persistência, autoconfiança, dedicação, proatividade, inovação, sabedoria para identificar e (re)criar novas oportunidades, além da capacidade para decidir por conta própria e administrar riscos.

Torna-se imprescindível ponderar, com base nas reflexões de Hashimoto (2013), que a motivação do intraempreendedor está diretamente relacionada com a liberdade de fazer o que se quer em prol da Organização, aliada ao prazer de conduzir seus próprios projetos, os quais resultarão em ganhos organizacionais coletivos.

Nessa seara analítica, Pinchot (1989), considera que as instituições públicas precisam reavaliar a relevância da criação de um ambiente que propicie a liberdade de atitude, a busca individual de novos conhecimentos e aprendizagem, a fim de suscitar e dar espaço ao desenvolvimento de perfis intraempreendedores entre os servidores públicos. As Organizações não poderão sobreviver por muito tempo com pessoas sem iniciativa, desmotivadas, presas às normas e burocracias. Torna-se necessário fomentar o desenvolvimento de características intraempreendedoras, sobretudo no serviço público, cujo o desafio neste sentido é bem maior (Pinchot, 1989).

\subsection{Reformas da Administração Pública Brasileira: a hora $e$ a vez do Intraempreendedorismo?}

Diante das novas práticas de gestão, as organizações públicas brasileiras têm vivenciado, nas últimas décadas, um grande processo de mudança de valores e quebra de paradigmas. De acordo com Silva (2013), esse processo de mudança precisa partir de um modelo de gestão burocrático e hierárquico para um modelo gerencial voltado ao alcance de resultados, com ênfase na qualidade e eficiência dos serviços prestados à sociedade.

Mais que uma mudança estrutural, as organizações públicas necessitam de uma mudança cultural. Silva $(2013$, p. 20) ressalta que, características como "apego às rotinas e às regras, supervalorização da hierarquia, paternalismo nas relações, apego ao poder, ostracismo, favoritismo, negligência e predomínio de critérios políticos nas decisões" precisam ser reavaliadas visando abrir espaço para implantação de práticas gerenciais.

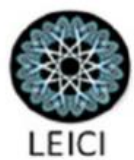


Partindo das considerações elencadas por Oliveira (2010), a administração pública contemporânea tem buscado a adoção de conceitos, discursos e práticas gerenciais típicas do mundo corporativo. Com efeito, o universo público tem procurado, cada vez mais, respostas no universo privado para atendimento das novas demandas da sociedade, visualizando o cidadão como um cliente que precisa de um atendimento de qualidade.

No entanto, foi necessário um longo processo de tentativas de reformas administrativas para se chegar a este momento, em que já é possível abordar a presença de características empreendedoras, bem como a possibilidade de construção de um ambiente intraempreendedor no setor público. Este cenário pode ser materializado com a adoção de práticas de sucesso importadas das Organizações privadas.

De acordo com Bresser-Pereira (1998), antes da Reforma Gerencial iniciada em 1995, o Brasil havia conhecido duas outras reformas administrativas. A primeira ocorreu no período do primeiro governo de Getúlio Vargas (1930-1945), chamada de reforma burocrática de 1936. Na esteira de Silva (1999), a administração pública burocrática, embasada no estilo clássico de administração, tem como princípios: centralização das decisões, hierarquia, estrutura piramidal de poder e controle rígido dos processos administrativos.

Tal Reforma tentou implantar, no Brasil, a administração pública burocrática em substituição à patrimonialista, que era marcada pelo patriarcalismo, paternalismo, nepotismo, empreguismo e falta de distinção entre o público e privado, estilo típico das Monarquias Absolutas (Bresser-Pereira, 1998).

Nesse segmento, Bresser-Pereira (1998) postula, ainda, que a segunda reforma administrativa no Brasil foi a chamada "Reforma Desenvolvimentista" de 1967, que considerava o mecanicismo e a burocracia rígida da Era Vargas um entrave para o desenvolvimento econômico do país.

Segundo os estudos desenvolvidos por Leite (2013), o Decreto Lei 200/1967 foi a primeira tentativa de introdução dos princípios da administração gerencial no Brasil. Este Decreto tentou impulsionar a administração pública para a eficiência e a descentralização administrativa, com base na autonomia da administração indireta. Trouxe os princípios da racionalidade administrativa, planejamento, orçamento, descentralização e controle de resultados. Ocorre, todavia, que a tentativa fracassou, pois abriu espaço para o retorno às práticas patriarcalistas e nepotistas: a contratação de servidores sem realização de concurso público, ausência de atenção à estrutura da administração direta e ao plano de carreira do alto escalão do Governo.

Assim, mesmo diante destes relatos de insucessos, Abrúcio (2007) afirma que as reformas administrativas brasileiras dos anos 30 e 60 foram significativas, uma vez que construiu as bases da estrutura burocrática do Estado brasileiro.

Impulsionada pelas mudanças que estavam ocorrendo no resto do mundo, a terceira reforma ocorreu nos anos 90. Importa destacar que, já nos anos 80, esta reforma foi iniciada no Reino Unido, Nova Zelândia, Austrália e nos EUA. Trata-se da Reforma Gerencial, que buscou promover e estimular a eficiência dos serviços prestados aos cidadãos pela administração pública. Para Leite (2013), o Estado, à época, passava por uma significativa crise notadamente marcada pelo insucesso dos planos econômicos implementados, descontrole fiscal, aumento do índice de desemprego, desvalorização monetária, além da ineficiência do modelo burocrático de Gestão Pública, o qual engessava de maneira geral os processos.

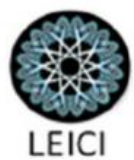


Diante disso, Bresser-Pereira (2005) pontua que o modelo gerencial surgiu como uma forma de enfrentar a crise fiscal do Estado, além de configurar uma estratégia para tornar a administração pública menos onerosa e mais eficiente, visando atender às novas demandas da sociedade, bem como as exigências oriundas da globalização.

Avaliando essas características apontadas por Bresser-Pereira (2005) no que tange à administração pública gerencial, percebe-se que neste modelo há espaço para o incentivo à criatividade e à inovação; possibilitando abertura para a construção de um ambiente intraempreendedor no setor público.

De acordo com Reis (2014), em cada uma dessas reformas administrativas foi definido um perfil de servidor público. Os traços dos funcionários do período patrimonialista demonstravam, abertamente, a existência de uma relação de fidelidade; aproximando-se da submissão existente entre criado e senhor de tempos passados. Nesse segmento, não havia comprometimento com as tarefas a serem executadas e com as regras; em suma: tratava-se de uma relação vulnerável que desaguava no nepotismo, empreguismo e, por conseguinte, na corrupção.

Já o modelo burocrático de administração é caracterizado pela formalização, previsibilidade, divisão do trabalho, hierarquia e pela impessoalidade. Nela, os servidores são escolhidos pela competência técnica e pela meritocracia. Um dos grandes problemas desse modelo é a rotina de tarefas que conduz ao mecanicismo dos processos, à morosidade e à ausência de qualidade nos resultados. No entanto, apesar de entraves como o excesso de formalismo e rigidez burocrática, este modelo contribuiu com a modernização da Administração Pública, reforçando, sobretudo, a meritocracia e a separação entre o público e o privado (Leite, 2013).

A partir deste modelo gerencial de administração pública, acredita-se ser possível o surgimento de mecanismos que colaborem com o desenvolvimento de um ambiente organizacional que fomente práticas intraempreendedores. Para Dornelas (2004), o entendimento de uma gestão empreendedora envolve um estilo gerencial de funções, papéis e atividades de administração para atingir seus objetivos de inconformismo em busca de inovação.

Neste ambiente, começa-se a abrir espaço para expressões como: criatividade, postura empreendedora, inovação, gestão por competências e por resultados. Com isso, torna-se necessária a construção/desenvolvimento de um novo perfil de servidor público (proativo, dinâmico, inovador), que corresponda às mudanças propostas pelo modelo de administração pública gerencial; amparado por procedimentos mais democráticos, meritocráticos e participativos.

\section{Procedimentos Metodológicos}

Partindo dos princípios analíticos preconizados por Diehl (2004), este trabalho pautouse na pesquisa descritiva, utilizando técnicas da abordagem qualitativa e quantitativa. Importa destacar que a abordagem qualitativa procura descrever a complexidade do problema estudado, além de contribuir no processo de mudança e possibilitar a compreensão das mais variadas características e particularidades dos indivíduos. Por sua vez, a segunda abordagem visa à quantificação tanto na coleta dos dados como no tratamento das informações, faz uso de

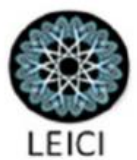


técnicas estatísticas, com o objetivo de evitar possíveis distorções na análise e interpretação dos resultados, o que garante maior margem de segurança.

A pesquisa descritiva, segundo Vergara (2007), expõe as características de determinada população ou fenômeno; estabelece correlações entre variáveis e define sua natureza. O método de análise dos dados é indutivo. O processo e seu significado são os focos principais de abordagem (Lakatos, \& Marconi, 1991). A utilização deste tipo de pesquisa permitirá a coleta, mensuração, análise e apresentação eficaz dos dados coletados.

$\mathrm{Na}$ fase inicial do trabalho empírico foi realizada uma Pesquisa Exploratória que, segundo Mattar (2005), tem como objetivo prover o pesquisador de um maior conhecimento sobre o tema ou problema de pesquisa. Na esteira dessa abordagem, foram coletados dados secundários em livros, revistas, jornais, entre outros. Para Gil (2008), os dados secundários caracterizam a pesquisa bibliográfica; é desenvolvida a partir de materiais já elaborados, constituídos especialmente por livros e artigos científicos.

Após a fundamentação teórica elaborada a partir da pesquisa bibliográfica foram coletados os dados primários, os quais, segundo Mattar (2005), são aqueles que ainda estão em posse dos pesquisados, que precisam ser coletados, tabulados e analisados para atender aos objetivos da pesquisa em andamento. Estes dados primários foram coletados mediante a aplicação de um questionário com perguntas fechadas, juntamente com o Teste Tendência Empreendedora Geral (TEG).

O universo da pesquisa englobou todos os servidores públicos técnico- administrativos da UFMS, lotados no Campus de Três Lagoas. Utilizou-se, para seleção da amostra, o processo de amostragem não probabilística que, segundo Mattar (2005, p. 271), trata-se da "[...] seleção dos elementos da população para compor a amostra [...]" e, por extensão, "[...] depende, ao menos em parte, do julgamento do pesquisador ou do entrevistador no campo".

O método aplicado foi a amostragem por julgamento ou intencional. Cumpre destacar que esse procedimento "[...] é uma técnica de amostragem não probabilística na qual um pesquisador experiente seleciona a amostra com base em seu julgamento pessoal sobre as características apropriadas dos membros da amostra" (Zikmund, 2006 p. 365).

Como critério de inclusão e exclusão dos componentes da amostra, considerou-se, como participantes, somente os questionários devolvidos, devidamente preenchidos, dentro do prazo estabelecido, ou seja, no interstício de 01 de agosto a 30 de setembro de 2015.

\subsection{Teste TEG - Tendência Empreendedora Geral: gênese e aplicabilidade}

O Teste Tendência Empreendedora Geral foi desenvolvido na Unidade de Produção Industrial da Durham University Business School, na Inglaterra, em 1988, a partir de estudos realizados por Sally Caird. De acordo com a autora, todos os indivíduos apresentam uma ou outra característica empreendedora em seu perfil comportamental. Sendo assim, conhecer a quantidade e o grau das características empreendedoras apresentadas é uma forma de identificar se o indivíduo possui ou não um comportamento empreendedor (Caird, 2008).

Com os resultados obtidos a partir dos estudos realizados com estudantes da Inglaterra, Caird validou o teste TEG em 1988, comprovando que os empreendedores possuem um conjunto de características que os distinguem dos demais indivíduos. Norteada pela revisão da literatura na área, as características confirmadas são:

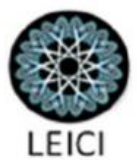


a. Necessidade de Sucesso: realização pessoal, visão futura, autossuficiência, otimismo diante das situações, orientação para tarefas e resultados, confiança em si, persistência, determinação/dedicação para concluir os projetos iniciados (Vedoin, 2010);

b. Necessidade de Autonomia/Independência: preferência por tomar suas próprias decisões, ao invés de receber ordens e ficar preso às regras impostas, necessidade de estar sempre à frente das mudanças. (Dornelas, 2007);

c. Tendência Criativa: capacidade de raciocínio alternativo, reúne qualidades de imaginação e inovação, versatilidade e curiosidade, intuição, gosto por novos desafios e abertura a mudanças. (Vendoin, 2010);

d. Propensão a Riscos: capacidade de lidar com decisões incompletas; assumir riscos calculados e gerenciá-los avaliando as reais possibilidades de sucesso (Dornelas, 2007);

e. Impulso/Determinação: capacidade de agir com base em novas oportunidades, antes de ser solicitado ou forçado pelos acontecimentos (Uriarte, 1999).

Vedoin (2010) aponta que o teste TEG é composto por 54 (cinquenta e quatro) afirmações, para as quais os respondentes optam por "Concordo (C)" ou "Não Concordo (N)". Todas as questões são direcionadas para corresponder às cinco características comuns a indivíduos com perfil empreendedor. Dessa maneira, seis questões estão relacionadas à característica "Necessidade de Autonomia" e doze questões referem-se as outras quatro características: "Necessidade de Sucesso", "Tendência Criativa", "Propensão a Riscos" e "Impulso/Determinação".

Como parâmetros para análise das médias obtidas com a aplicação do TEG pelo pesquisador, Ferreira \& Aranha (2008) apresentam as médias propostas por Caird (2008), sendo, de um lado, a pontuação máxima do teste; de outro, a média esperada:

Quadro 1: Metodologia para análise da média das cinco características do perfil empreended
\begin{tabular}{|l|c|c|}
\hline \multicolumn{1}{|c|}{ Característica } & Pontuação Máxima & Média Esperada \\
\hline Necessidade de Sucesso (S) & 12 & 9 \\
\hline Necessidade de Autonomia Independência (AI) & 6 & 4 \\
\hline Tendência Criativa (TC) & 12 & 8 \\
\hline Propensão a Riscos (PR) & 12 & 8 \\
\hline Impulso e Determinação (ID) & 12 & 8 \\
\hline
\end{tabular}

Fonte: Adaptado de Ferreira e Aranha (2008, p. 5)

$\mathrm{Na}$ esteira de Dornelas (2007), não se pode afirmar que exista um padrão de comportamento para os indivíduos empreendedores, mas que existam características comuns encontradas nestes indivíduos que os diferenciam dos demais. Essas características nem sempre são natas; portanto, podem ser desenvolvidas ao longo da vida pela visualização de oportunidades ou até mesmo pela necessidade de sobrevivência. A partir desta visão, pode-se constatar que o perfil empreendedor é algo que pode ser desenvolvido em qualquer indivíduo; em qualquer período da vida.

O Teste TEG assume extrema relevância, uma vez que possibilita a identificação e mensuração do perfil empreendedor do indivíduo, tornando possível afirmar até que ponto uma 
determinada pessoa possui ou não características específicas do comportamento empreendedor, analisando as cinco dimensões apresentadas.

Nesse estudo, os resultados do TEG permitiram identificar o nível do perfil intraempreendedor da equipe de técnico-administrativos do Campus de Três Lagoas, tendo em vista que as cinco características avaliadas pelo TEG vão ao encontro do que Pinchot (1989) define como características intraempreendedoras: autoconfiança, otimismo, orientação para resultados, necessidade de agir, prazer em realizar pequenas tarefas, visão e ação, dedicação, prioridades, metas, superação de erros e administração de riscos. Nesta mesma linha, Fernald \& Solomon (1987), citado por Malafaia, Azevedo \& Barcelos (2011, p. 215) constataram características comuns aos empreendedores, como: "habilidade para identificar oportunidades; conhecimento de sua área de atuação; senso de organização; disposição para tomar decisões; capacidade de liderança; talento para empreender; independência pessoal; otimismo".

A aplicação do teste TEG para identificar as características empreendedoras de servidores públicos da área administrativa de uma instituição federal, além do seu ineditismo, proporcionou conhecimentos de extrema relevância em tempos de predominância da administração pública gerencial.

\section{Análises e Propostas de Inovação e Contribuição Social}

A pesquisa contou com a participação de 53 servidores, compreendidos entre os 70 que compõem, atualmente, o corpo técnico-administrativo do CPTL/UFMS, o que corresponde a $76 \%$ do total. Sendo que, dos "não-respondentes", 02 técnicas estão em licença para acompanhamento de cônjuge, 01 está afastada para pós-graduação, 01 está em exercício temporário em outra unidade da UFMS, 02 estão em licença para tratamento de saúde e 11 técnicos não manifestaram interesse em participar da pesquisa. A coleta de dados ocorreu no período de 01 de agosto a 30 de setembro de 2015.

Os dados coletados foram tabulados com a utilização de estatística descritiva básica, com o auxílio do software Microsoft Excel 2010, em conformidade com a metodologia proposta pelo TEG (Caird, 2008). A forma de interpretação compreendeu uma análise indutiva, tendo como alicerce a revisão bibliográfica realizada e os conhecimentos adquiridos ao longo do desenvolvimento da pesquisa.

Os participantes foram, em sua maioria, homens, conforme dados da Tabela 1. A faixa etária predominante está compreendida no intervalo de 31 a 40 anos. Estes dados revelam o perfil jovial da equipe administrativa do CPTL, pois somando-se os dois maiores percentuais, obtém-se $60,38 \%$ de participantes com idade entre 18 e 40 anos.

Tabela 1: Faixa etária dos Técnico-administrativos do CPTL

\begin{tabular}{l|ccr}
\multicolumn{1}{c}{ FAIXA ETÁRIA } & MASC & FEM & \% TOTAL \\
18 a 30 anos & 8 & 7 & 28,30 \\
31 a 40 anos & 11 & 6 & 32,08 \\
41 a 50 anos & 3 & 5 & 15,09 \\
Acima de 50 anos & 7 & 6 & 24,53 \\
TOTAL & 29 & 24 & 100,00
\end{tabular}

Fonte: Dados coletados pela autora no período de agosto-setembro/2015 
Em relação ao grau de escolaridade, conforme dados dispostos na Tabela 2, a maioria possui pós-graduação, 50,94\% o que demonstra o nível de capacitação da equipe. Neste percentual estão englobados 14 servidores com Especialização e 13 com Mestrado, além de 16 servidores que, apesar de ocuparem cargos de nível médio, possuem nível superior completo.

Tabela 2: Grau de Escolaridade dos Técnico-Administrativos do CPTL

\begin{tabular}{l|ccc} 
GRAU DE ESCOLARIDADE & MASC & FEM & \% TOTAL \\
\hline Ensino médio & 6 & 4 & 18,87 \\
Ensino superior & 11 & 5 & 30,19 \\
Pós-graduação & 12 & 15 & 50,94 \\
TOTAL & 29 & 24 & 100,00
\end{tabular}

Fonte: Dados coletados pela autora no período de agosto-setembro/2015

Somando o percentual de pós-graduados e graduados obtém-se $81,13 \%$, o que revela o interesse dos servidores na busca pelo aperfeiçoamento contínuo para o crescimento profissional e para o aumento nos ganhos salariais. De acordo com a Lei 11.091/2005 no seu anexo IV - que trata do plano de carreira dos servidores técnico-administrativos em educação a capacitação no nível de graduação gera um adicional de $25 \%$ sobre o salário base, para o servidor cujo cargo efetivo seja de nível médio e 5\% a mais, caso curse uma especialização. Já para os cargos de nível superior, a graduação é pré-requisito para a posse, e a especialização gera um adicional de $30 \%$ sobre o salário base. Tanto para os cargos de nível médio como para superior, o Mestrado garante um adicional de 52\% sobre o salário base e o doutorado um adicional de $75 \%$.

Indagados sobre a atuação ao longo da carreira profissional, 58,49\% dos servidores respondentes afirmaram ter trabalhado em empresa privada, conforme demonstrado na Tabela 3:

Tabela 1: Atuação profissional dos Técnico-administrativos do CPTL

\begin{tabular}{l|cccc}
\multicolumn{1}{c}{ ATUAÇÃO PROFISSIONAL } & MASC & FEM & \% TOTAL \\
\hline Sempre trabalhei no serviço público & 10 & 5 & 28,30 \\
Já trabalhei em empresa privada & 13 & 18 & 58,49 \\
Já fui proprietário de empresa & 2 & 0 & 3,77 \\
Já trabalhei como autônomo & 4 & 1 & 9,43 \\
\multicolumn{1}{c}{ TOTAL } & 29 & 24 & 100,00
\end{tabular}

Fonte: Dados coletados pela autora no período de agosto-setembro/2015

A experiência da maioria dos servidores na iniciativa privada pode revelar um campo fértil para a aplicação dos conceitos gerenciais na execução de suas tarefas no serviço público, com a prática de princípios relacionados à eficiência, qualidade dos resultados, descentralização, flexibilidade e proatividade. 


\subsection{Resultado do Teste Tendência Empreendedora Geral (TEG)}

O Gráfico 1 apresenta o resultado do TEG entre os servidores do sexo masculino. Foi obtido resultado acima da média esperada apenas na característica "impulso/determinação" atingindo 9,03 pontos. De acordo com Lira et al. (2005), os indivíduos que nutrem esta característica sabem aproveitar as oportunidades, não acreditam em predeterminação, confiam em si e aliam esforço com foco em resultados.

Gráfico 1: Tendência Empreendedora Geral dos servidores do sexo masculino do CPTL

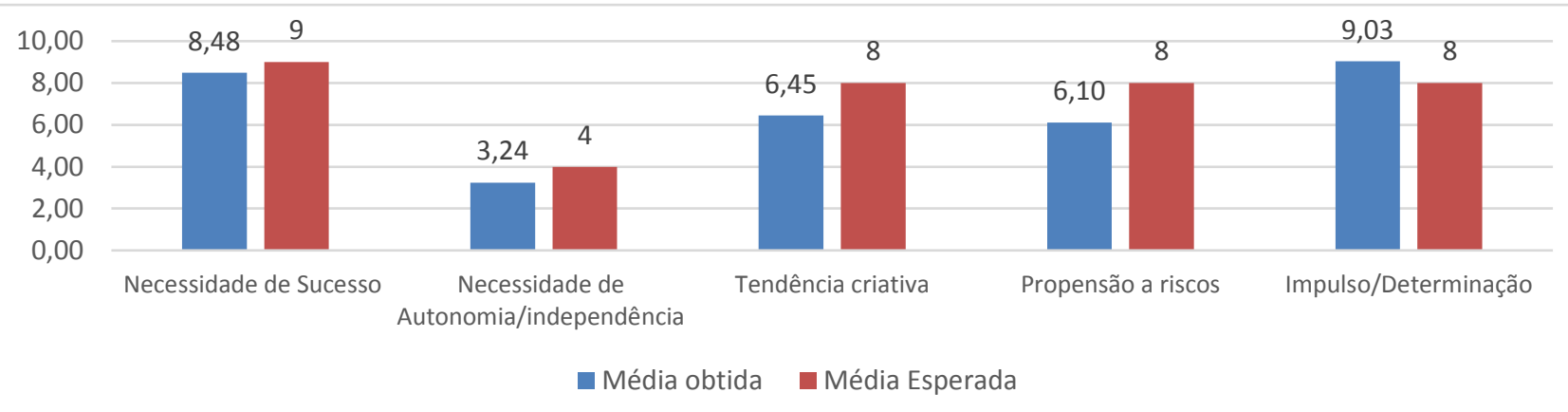

Fonte: Dados coletados pela autora no período de agosto-setembro/2015

Na característica "Necessidade de Sucesso" foi obtida pontuação próxima à média esperada, somando 8,48. Para Caird (2008), a "Necessidade de Sucesso" está relacionada com a realização pessoal, todavia é preciso evitar excessos, que podem conduzir a uma busca desenfreada pelo poder.

As características "Tendência Criativa e Propensão a Riscos" distanciaram, sobremaneira, da média esperada. Este fato pode estar relacionado à estabilidade que o serviço público garante ao servidor e à excessiva burocracia, que muitas vezes causa prejuízo ao andamento das atividades, não havendo espaço para a inovação, criatividade e novidade.

O Gráfico 2 apresenta o resultado do TEG entre os servidores do sexo feminino. Percebe-se que entre as mulheres a única característica que também ultrapassou a média esperada foi "Impulso/Determinação" com 9,58 pontos. Esse dado revela que as mulheres também buscam as oportunidades e vislumbram construir um futuro promissor (Uriarte, 1999).

Gráfico 2: Tendência Empreendedora Geral dos servidores do sexo feminino do CPTL

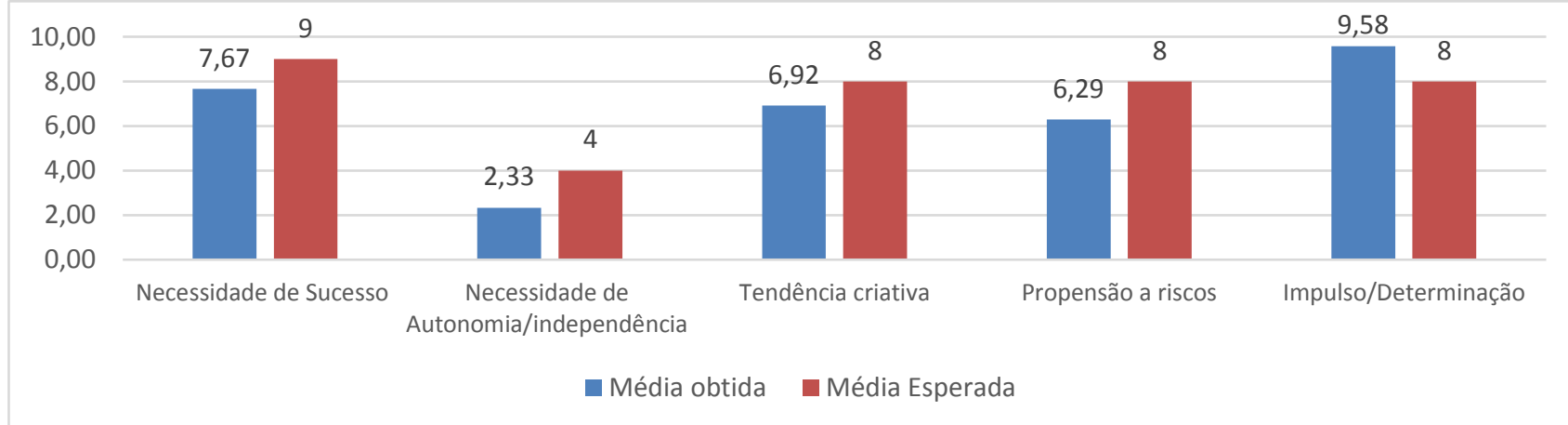

Fonte: Dados coletados pela autora no período de agosto-setembro/2015 
A característica "Tendência Criativa" alcançou uma pontuação que se aproxima da média esperada, somando 6,92 pontos. Este resultado pode estar relacionado a presença de elementos próprios do universo feminino, como criatividade, sensibilidade e abertura à novidade. Nesse segmento, comparando os resultados dos gráficos 1 e 2 constata-se que o gênero não é determinante para a presença/ausência de características empreendedoras no perfil do indivíduo. Com efeito, tanto os homens como as mulheres só obtiveram pontuação acima da média na característica "Impulso/Determinação".

O Gráfico 3 apresenta o resultado geral do teste Tendência Empreendedora Geral dos técnico-administrativos do Campus de Três Lagoas. Os resultados obtidos revelam que apenas a característica "Impulso/Determinação" obteve pontuação acima da média:

Gráfico 3: Tendência Empreendedora Geral dos Técnico-administrativos do CPTL

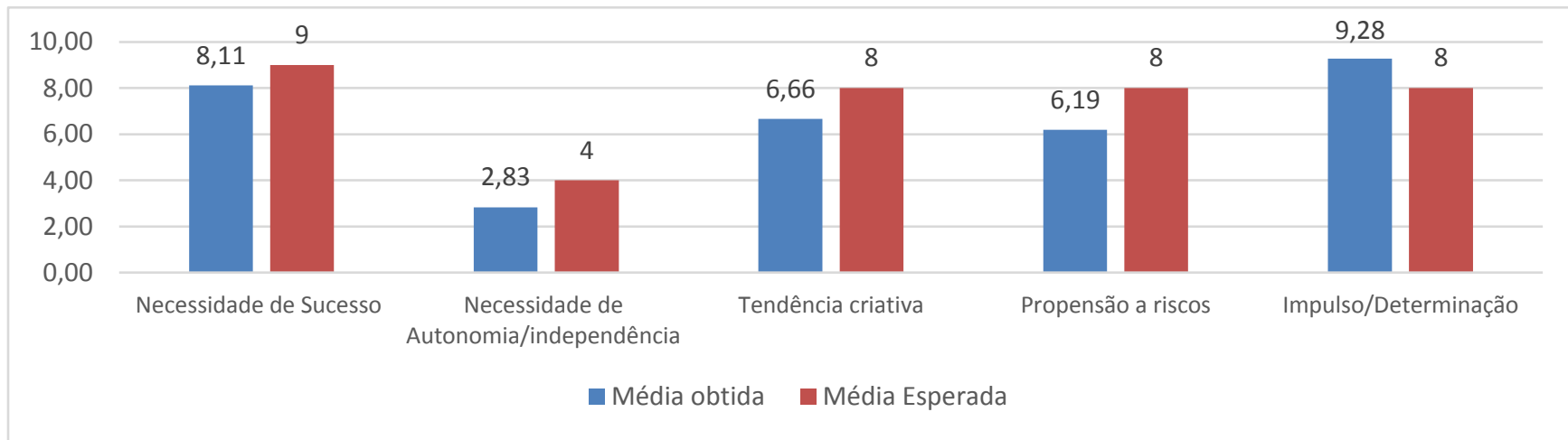

Fonte: Dados coletados pela autora no período de agosto-setembro/2015

Ancorado pelos estudos de Pantzier (1999), esse resultado acima da média em “ Impulso/Determinação" revela que os respondentes se caracterizam por saber aproveitar as oportunidades e não acreditar em predeterminação.

Nas últimas décadas, essa característica vem sendo fomentada na Administração Pública pelos conceitos gerenciais com as seguintes medidas adotadas: valorização do servidor, melhoria das suas condições de remuneração, transparência e rigor no recrutamento e na avaliação de desempenho (Silva, 1999). Esses fatores poderão contribuir com a redução da passividade na administração pública e promover o maior comprometimento do servidor público com a prestação de serviço de qualidade à sociedade.

As demais características ficaram bem abaixo do esperado pelo teste TEG, revelando existir, ainda, um longo caminho a ser trilhado pela Instituição para a promoção de um ambiente mais propício ao surgimento, ao cultivo e a permanência de profissionais com perfil intraempreendedor.

O destaque negativo foi "Propensão a Riscos", que atingiu menor score em relação ao esperado, ou seja, praticamente 1,81 ponto abaixo da média proposta. De acordo com Peloggia (2001), a baixa pontuação nesta característica evidencia a dificuldade do indivíduo em atuar com informações incompletas, o medo de enfrentar tarefas que julga serem complicadas e desafiadoras, as quais desafiam os limites de sua capacidade. Essa característica é relevante para a construção de um perfil empreendedor. Seguindo os pressupostos de Dornelas (2007), torna-se necessário, no tocante à Administração Pública, a presença de servidores com esse

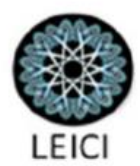


perfil; que sejam capazes de calcular riscos e que possam prever, antecipadamente, quais ações devem ser tomadas caso ocorram imprevistos.

"Tendência Criativa" ficou 1,44 pontos abaixo do esperado. Para Caird (2008), essa característica está relacionada à capacidade de dinamismo, versatilidade, curiosidade, imaginação e inovação, que leva à transformação de ideias viáveis em grandes realizações concretas. O resultado, muito abaixo da média esperada, revela que os técnico-administrativos do Campus de Três Lagoas apresentam resistência em lidar com a novidade e a mudança; preferem a rotina e temem novos desafios; são reticentes ao cultivo de novas ideias, fato que inibe a capacidade de buscar novos caminhos para melhoria no desempenho e obtenção de resultados mais eficientes e eficazes na prestação dos seus serviços à sociedade.

Quanto à "Necessidade de Autonomia/Independência", o resultado foi inferior à média, praticamente 1,17 ponto a menos. Pantzier (1999) assevera que essa característica está relacionada à persistência e determinação, preferência por realizar atribuições pouco convencionais, gosto por tomar decisões sem a necessidade de receber ordens. Esse resultado, inferior ao esperado, demonstra que os técnico-administrativos preferem executar atividades convencionais, sendo sempre coordenados por outras pessoas que assumam as responsabilidades pelas decisões. Ao invés protagonizarem a própria história, visando maior êxito na carreira profissional, preferem permanecer em uma zona de conforto, recebendo/cumprindo ordens. A estabilidade que o serviço público garante e o modelo burocrático institucional corroboram para manter reduzida esta característica nos servidores.

Trazendo à baila os estudos de Peloggia (2001), a característica "Necessidade de Sucesso" chegou bem próxima à média esperada, abaixo apenas 0,89 ponto. Essa proximidade da média revela que os técnico-administrativos possuem características como otimismo, orientação para tarefas e resultados, confiança em si, em seus conhecimentos e habilidades. Essa característica se reforça também, pela busca de aperfeiçoamento profissional, que é uma marca característica da equipe técnica do Campus de Três Lagoas, e pelo desejo de manteremse atualizados. Com a aplicação do questionário, constatou-se o elevado percentual de servidores que possuem grau de escolaridade superior ao exigido pelo cargo. Embora percebase um vínculo primário entre o aperfeiçoamento profissional e os ganhos financeiros, esse fator contribui para melhoria no desempenho organizacional.

\subsection{Contribuições para a Organização e a Sociedade}

Os resultados deste estudo poderão despertar, nas chefias e gestores da Instituição, um olhar diferenciado para a equipe administrativa, a partir do entendimento da sua contribuição para a melhoria no desempenho organizacional.

A pesquisa apresenta relevância para a comunidade acadêmica e a sociedade em geral. Tais ganhos poderão ser percebidos a partir de tempos de espera reduzidos, agilidade no atendimento das demandas, redução do excesso de burocracia e maior qualidade nos serviços prestados. Esse upgrade poderá ser alcançado a partir da autoanálise dos servidores técnicoadministrativos e da abertura dos chefes e gestores às sugestões do presente estudo. Na Tabela 7, são apresentadas algumas propostas de estímulo ao intraempreendedorismo:

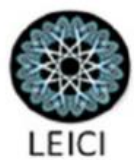




\section{Tabela 5: Propostas de estímulo a um ambiente intraempreendedor no CPTL/UFMS}

\begin{tabular}{|c|c|c|c|}
\hline Diretrizes & Ação Prioritária & Meios de Implementação & Atores Envolvidos \\
\hline $\begin{array}{l}\text { - Desenvolvimento de um } \\
\text { programa com ações que } \\
\text { visem fomentar o } \\
\text { surgimento e a manutenção } \\
\text { do intraempreendedorismo } \\
\text { no Campus de Três Lagoas. }\end{array}$ & $\begin{array}{l}\text { - Fazer um diagnóstico da } \\
\text { situação atual; } \\
\text { - Definir as prioridades; } \\
\text { - Elaborar e implementar plano } \\
\text { de ação; } \\
\text { - Dividir as responsabilidades; } \\
\text { - Realizar avaliações e feedbacks } \\
\text { periódicos. }\end{array}$ & $\begin{array}{l}\text { - Reuniões periódicas; } \\
\text { - Definição de objetivos e metas } \\
\text { para cada setor, em conjunto; } \\
\text { - Maior abertura para a } \\
\text { implementação das sugestões da } \\
\text { equipe. }\end{array}$ & $\begin{array}{l}\text { Diretor do } \\
\text { CPTL; chefes de } \\
\text { lotação; técnico- } \\
\text { administrativos. }\end{array}$ \\
\hline $\begin{array}{l}\text { - Fomento de um ambiente } \\
\text { de tolerância aos riscos e } \\
\text { erros que poderão vir de } \\
\text { inovações e e ideias } \\
\text { empreendedoras. }\end{array}$ & $\begin{array}{l}\text { - Calcular os riscos das } \\
\text { mudanças e fazer o devido } \\
\text { acompanhamento para evitar } \\
\text { problemas que desestimulem } \\
\text { novas tentativas de inovação. }\end{array}$ & $\begin{array}{l}\text { - Mapeamento de riscos } \\
\text {-Elaboração de matriz de riscos } \\
\text { (impacto x probabilidade). } \\
\text {-Tratamento dos riscos } \\
\text { identificados (eliminação, } \\
\text { mitigação ou aceitação). }\end{array}$ & $\begin{array}{l}\text { - Diretor do CPTL; } \\
\text { chefes de lotação; } \\
\text { técnico- } \\
\text { administrativos. }\end{array}$ \\
\hline $\begin{array}{l}\text {-Flexibilidade para } \\
\text { mudanças provocadas } \\
\text { pelas inovações e para a } \\
\text { implantação do sistema de } \\
\text { gestão da inovação. }\end{array}$ & $\begin{array}{l}\text { - Criar espaço para que os } \\
\text { técnicos participem, } \\
\text { efetivamente, das decisões que } \\
\text { afetam diretamente seu ambiente } \\
\text { de trabalho, a fim de que tenham } \\
\text { maior autonomia para mudanças } \\
\text { e inovações, e possam agir de } \\
\text { maneira proativa no dia-a-dia, } \\
\text { com dinamismo e flexibilidade, } \\
\text { sem comprometerem, no } \\
\text { entanto, as normas e regras } \\
\text { institucionais. }\end{array}$ & $\begin{array}{l}\text { - Reuniões setoriais; } \\
\text { - Mural de Sugestões; } \\
\text {-Mapeamento dos processos } \\
\text { atuais; } \\
\text {-Reformulação e melhorias de } \\
\text { processos para agilidade e } \\
\text { qualidade no atendimento das } \\
\text { demandas. }\end{array}$ & $\begin{array}{l}\text { - Diretor do CPTL; } \\
\text { chefes de lotação; } \\
\text { técnico- } \\
\text { administrativos. }\end{array}$ \\
\hline $\begin{array}{l}\text { - Estímulo à cultura do } \\
\text { aprendizado na Instituiçãa } \\
\text { para a evolução constante; } \\
\text { à busca de novos } \\
\text { conhecimentos e técnicas } \\
\text { para melhoria no } \\
\text { desempenho } \\
\text { organizacional. }\end{array}$ & $\begin{array}{l}\text {-Incentivar e promover a } \\
\text { qualificação dos técnico- } \\
\text { administrativos; } \\
\text { - Oferecer oportunidades } \\
\text { igualitárias de treinamento e } \\
\text { capacitação para os servidores da } \\
\text { Capital e dos Campi do interior } \\
\text { da UFMS. }\end{array}$ & $\begin{array}{l}\text { - Videoconferência, recursos } \\
\text { tecnológicos; } \\
\text { - Prover meios (diárias e } \\
\text { passagens) para que os técnicos } \\
\text { dos Campi do interior possam } \\
\text { participar dos treinamentos } \\
\text { realizados pela Pró-Reitoria de } \\
\text { Gestão de Pessoas (PROGEP) e } \\
\text { outros que sejam pertinentes. }\end{array}$ & $\begin{array}{l}\text { - Pró-Reitor de } \\
\text { Gestão de Pessoas; } \\
\text { Pró-Reitor de } \\
\text { Planejamento; } \\
\text { Diretor do CPTL; } \\
\text { chefes de lotação; } \\
\text { técnico- } \\
\text { administrativos. }\end{array}$ \\
\hline
\end{tabular}

Fonte: a autora, 2015.

Dessa forma, almeja-se que os dados contidos na presente pesquisa contribuam para que seja entendida a relevância de incentivar/promover a qualificação destes servidores, valorizar as atividades que desempenham, criar espaço para que participem, efetivamente, das decisões que afetam seu ambiente de trabalho. Assim, terão mais autonomia para mudanças e inovações, sendo estimulados a agir de maneira proativa no dia-a-dia, com dinamismo e flexibilidade; sem, no entanto, comprometerem as normas e regras institucionais.

O estudo trouxe também benefícios relacionados à percepção de falhas que precisam ser corrigidas pela própria equipe, sobretudo no que se refere à agilidade na execução de tarefas 
e processos. Promoveu, também, o autoconhecimento dos servidores participantes, que em sua maioria, ainda não haviam participado de pesquisa semelhante.

Portanto, em tempos de predomínio da Administração Pública Gerencial, os resultados dessa pesquisa poderão nortear outras Instituições Públicas que também almejam estimular o intraempreendedorismo em seu ambiente organizacional.

\section{Considerações Finais}

Diante dos resultados apresentados, constata-se que há um considerável caminho a ser percorrido pelo Campus de Três Lagoas/UFMS para a criação e o fomento do intraempreendedorismo em seu ambiente organizacional. O excesso de burocracia e formalismo impedem o surgimento de práticas inovadoras, barram a proatividade e a promoção de melhorias no desempenho organizacional.

Embora apresente potencial para promoção de inovações e melhorias, com uma equipe administrativa relativamente jovem (entre 18 e 40 anos); bem qualificada (com significativo número de especialistas e mestres) os servidores ainda se encontram limitados pelo modelo arcaico de Administração Pública, o qual permanece camuflado atrás da aparente modernização tão referenciada pela Reforma Gerencial.

Um fato que pode confirmar o apego à estabilidade e ao status quo é a superação da média em apenas uma das cinco características comumente encontradas em indivíduos com perfil empreendedor: "Impulso/Determinação". Esse dado revela que os servidores participantes da pesquisa não possuem características empreendedoras natas e que a Instituição também não corrobora com o desenvolvimento destas características, as quais promovem a melhoria do desempenho de qualquer Organização Pública ou Privada.

Ao final do estudo, como forma de contribuição social, foram sugeridas propostas de estímulo à criação e manutenção de um ambiente intraempreendedor que poderão ser adotadas, também, por outras Instituições Públicas que almejam, efetivamente, fomentar a inovação e a melhoria do seu desempenho organizacional.

\section{Referências}

Abrucio, F. L. (1998). Os avanços e dilemas do modelo pós-burocrático: a reforma da Administração Pública à luz da experiência internacional recente. In: Bresser Pereira, Luiz Carlos; Spink, Peter. A Reforma do Estado e a Administração Pública Gerencial. São Paulo: Fundação Getúlio Vargas.

Abrucio, F. L (2007). Trajetória recente da gestão pública brasileira: um balanço crítico e a renovação da agenda de Reformas. Revista de Administração Pública: Rio de Janeiro. Edição Especial Comemorativa 1967-2007. p. 67-86.

Brasil. Secretaria de Gestão do Ministério do Planejamento, Orçamento e Gestão (2000). Gestão Pública Empreendedora. Brasília, 2000. Recuperado de http://livros01.livrosgratis.com.br/p1000027.pdf.

Bresser-Pereira, L. C. (1996, jan-abr.). Da Administração Pública Burocrática à Gerencial, Revista do Serviço Público, Brasília, DF, ano 47, v.120, n.1, p. 7-29. 
Bresser-Pereira, L. C. (1998). Reforma do Estado para a cidadania: a reforma gerencial brasileira na perspectiva internacional. São Paulo: Editora 34; Brasília: ENAP.

Bresser-Pereira, L. C., \& Spink, P. K. (2005). Reforma do Estado e Administração Pública Gerencial. 7. Ed. Rio de Janeiro: Editora FGV.

Caird, S. (1988, agosto). A review of measuring enterprise attributes. General measure of enterprising tendency. In Worldwide Interest in GET, 2008. Recuperado de http://www.get2test.net/index.html\#home.

Caird, S. (1990). Enterprise competencies: an agenda for research. Journal of European Industrial Training, 14, n.7, p. 3-8.

Caird, S. (1991). Testing enterprising tendency of occupational groups. British Journal of Management, v. 2, p. 177-186.

Dalfovo, M. S., Lana, R. A., \& Silveira, A. (2008). Métodos quantitativos e qualitativos: um resgate teórico. Revista Interdisciplinar Científica Aplicada, Blumenau, v.2, n.4, p.01-13, Sem II. 2008. ISSN 1980-7031.

Diehl, A. A. (2004). Pesquisa em ciências sociais aplicadas: métodos e técnicas. São Paulo: Prentice Hall.

Dornelas, J. C. A. (2004, abril-junho). Empreendedorismo Corporativo: Conceitos e Aplicações. Revista de Negócios, Blumenau, v. 9, n. 2, p. 81-90.

Dornelas, J. C. A. (2007). Empreendedorismo na prática: mitos e verdades do empreendedor de sucesso. Rio de Janeiro: Elsevier.

Dornelas, J. C. A. (2008). Empreendedorismo: transformando ideias em negócios. 3. ed. Rio de Janeiro: Elsevier.

Ferreira, R. C., \& Aranha, E. A. (2008). Análise do perfil empreendedor de graduados em Engenharia de Produção Mecânica. Universidade Federal de Itajubá. MG: UNIFEII.

Fontoura, D. S. (2010). Mercado de trabalho no setor público: um olhar sobre uma unidade da Secretaria da Receita Federal do Brasil (Dissertação do Programa de Pós-Graduação em Administração). Universidade Federal do Rio Grande do Sul, Escola de Administração.

Global Entrepreneurship Monitor (GEM, 2017). Empreendedorismo no Brasil: 2016. Coordenação de Simara Maria de Souza Silveira Greco. Curitiba: IBQP.

Hashimoto, M. (2013). Espírito Empreendedor nas Organizações: aumentando a competitividade através do intraempreendedorismo. 3 ed. São Paulo: Saraiva.

Lakatos, E. M., \& Marconi, M. A. (1991). Metodologia Científica. 2. ed. São Paulo: Atlas.

Leite, L. Q. (2013, 21 a 23 de maio). A Trajetória da Reforma do Estado no Brasil: a Caminho de uma Administração Pública Gerencial? I Semana de Pós-Graduação em Ciência Política UFSCAR: Universidade Federal de São Carlos-SP.

Lezana, Á. G. R., \& Tonelli, A. (1998). O comportamento do empreendedor. In.: MORI, F. Empreender: Identificando, avaliando e planejando um novo negócio. ENE: UFSC. 
Lira, H. L., Lira, W. S., \& Morais, C. R. S. (2005).Empreendedorismo e Engenharia. Qualit@s - Revista Eletrônica - ISSN 1677- 4280, Volume 4, n. 2.

Malafaia, G.C., Azevedo, D. B., \& Barcelos, J. T. (2011). Empreendedorismo e Mecanismos de Coordenação na Pecuária. Revista Brasileira de Zootecnia / Brazilian Journal of Animal Science, v. 40, p. 195-203, 2011.

Mattar, F. N. Pesquisa de Marketing. São Paulo: Atlas, 2005.

Oliveira, F.B., Sant'ana, A.S., \& Vaz, S.L (2010). Liderança no contexto da nova administração pública: uma análise sob a perspectiva de gestores públicos de Minas Gerais e Rio de Janeiro. Recuperado de http://www.scielo.br/pdf/rap/v44n6/a09v44n6.pdf.

Osborne, D., \& Gaebler, T. (1994). Reinventando o Governo: como o espírito empreendedor está transformando o setor público. Brasilia, D.F.: MH Comunicação.

Pantzier, R. D (1999). Empreendedorismo e Formação de Administradores: uma análise do curso de administração da Universidade Regional de Blumenau (Dissertação de Mestrado). Blumenau CCSA: FURB.

Peloggia, L. R. (2001). Perfil empreendedor do engenheiro na produção industrial: O caso de duas empresas aeronáuticas no Brasil (Monografia apresentada ao Curso de MBA em Gerência de Produção e Tecnologia). Universidade de Taubaté: São Paulo.

Pinchot, G. (1985). Intrapreneuring: Por que você não precisa deixar a empresa para tornarse um empreendedor. Tradução Nivaldo Montingelli Jr. São Paulo: Harbra.

Pinchot, G. (1989). Intrapreneuring. Por que você não precisa deixar a empresa para tornarse um empreendedor. São Paulo: Harbra.

Pinchot, G.,\& Pellman R. (2004). Intraempreendedorismo na Prática: um guia de inovação nos negócios. Tradução Márcia Nascentes. Rio de Janeiro: Elsevier.

Silva, C. O.P. (1999). A Reforma Administrativa e a Emenda $n^{\circ}$ 19/98: Uma Análise Panorâmica. Revista Jurídica Virtual. Brasília, vol. 1, n. 1, maio 1999. Recuperado de http://www.planalto.gov.br/ccivil_03/revista/Rev_01/Reforma\%20Administrativa.htm.

Silva, S. A. (2013). Mudanças de Cenário e Impactos na Cultura Organizacional em uma Instituição de Ensino Superior. (Dissertação apresentada ao Mestrado Profissional em Gestão em Organizações Aprendentes). Universidade Federal da Paraíba, João Pessoa.

Uriarte, L. R. (1999). Tendência empreendedora das profissões. Anais. I Encontro Nacional de Empreendedorismo. ENE. UFSC.

Vedoin, A. M. R. (2010). Tendência Empreendedora: Perfil dos Alunos do Curso de Arquivologia da Universidade Federal de Santa Maria. (Monografia apresentada ao Curso de Especialização Lato-Sensu Gestão em Arquivos). Universidade Federal de Santa Maria, Rio Grande do Sul.

Vergara, S. C. (2007). Projetos e Relatórios de Pesquisa em administração. 9. ed. São Paulo: Atlas. 